\title{
DEVELOPMENT AND IMPLEMENTATION OF AN ADAPTIVE CRUISE CONTROL SYSTEM WITH A CUSTOMIZED ENGINE CONTROL UNIT
}

\author{
Sebastian Mroginski Kapelius ${ }^{1}$, Pedro Augusto Ebert Gatti ${ }^{1}$, Armando Antônio Maria \\ Laganá1, Bruno Augusto Angélico ${ }^{1}$ \\ ${ }^{1}$ Escola Politécnica da Universidade de São Paulo (EPUSP) \\ E-mails: seb.kape@gmail.com, p.gatti@hotmail.com, lagana@lsi.usp.br, \\ angelico@lac.usp.br
}

\begin{abstract}
This paper describes the development of an adaptive cruise control system (ACC), a driving assistant system, whose purpose is to control the vehicle's speed, determined by a setpoint inputted by the driver. Simultaneously, the system must also monitor the environment and adjust the car's velocity in order to maintain a safety distance from the other vehicles driving on the lane. This system's main purpose is to increase the driver's comfort, thus making it so he will no longer be required to control the throttle pedal and therefore be able to focus on the other tasks involved in driving.

For the speed control to be possible, the system communicates with an open engine control unit (ECU), developed by the Automotive Engineering Group (group formed by researchers members of Escola Politécnica da USP and of Faculdade de Tecnologia de Santo André) as well as with an automotive radar, installed on the vehicle's front bumper, responsible for measuring relative distance and relative speed to the other vehicles driving on the road. As the vehicle used does not have brake-bywire technologies implemented, the speed reducing is done via engine breaking. After its development, the system was implemented on a Volkswagen Polo 2004 and its performance was validated with tests on an inertial dynamometer and with road tests.
\end{abstract}

\section{INTRODUCTION}

The number of automotive vehicles on the streets has been raising throughout history and this increase can be accompanied by social, economic and environmental problems. In addition, the number of accidents has been growing on the recent years, as road traffic injuries were the $8^{\text {th }}$ leading cause of death for people of all ages on 2016 and were the leading cause of death for children and young adults (5-29 years of age) on that same year, according to the WHO [1]. This situation can be changed, however, with the development of safety systems, either passive safety systems, that help mitigate damage in the occurrence of an accident, or active safety systems, which help preventing accidents.

Advanced driver assistance systems (ADAS) can be used as an active safety system. Those systems can assist the drivers by providing extra information about the 
environment or by taking over on some control tasks of the driving process. Each ADAS can be implemented on a vehicle independently or multiple systems can work together towards an autonomous driving.

Among ADAS, longitudinal vehicle speed control is one of the most active topics of research [2]. One of these technologies is the adaptive cruise control (ACC), an evolution of the cruise control (CC). The CC system is responsible for maintaining the vehicle at a constant speed, accordingly to a setpoint, determined by the driver. The ACC, however, besides controlling the vehicle speed, is also responsible for maintaining a safety distance from the vehicle ahead, in order to avoid frontal collisions. This is done using data acquired by sensors installed on the vehicle, no information must be sent by an external source and the system does not depend on previously installed structures on the road. Several sensors can be used for this purpose, such as radars, cameras, LiDARs, etc.

Many ACC researches have been done, with different control theories being applied, such as MPC [3] and Fuzzy [4]. Some papers also do a comparison between different control technics, like [5] and [6]. Most of those papers, however, do not have a practical implementation, validating only via computer simulations or implement the system via an actuator directly on the pedals, like is done on [7], and not by communicating to the electronic control units from the vehicle. There are also studies evaluating the impact of the ACC system on traffic jam formation, average velocity on the road, flow rate on the road, driver reaction time, environmental impacts and energetic efficiency such as [8], [9], [10] and [11].

This paper describes the development of an adaptive cruise control system and its implementation on a test vehicle. The ACC module receives data from the ECU and from a radar sensor, processes and interprets it and then sends control signals to the ECU. The system is then validated on a safe and controlled test environment.

This paper is organized as follows: on the first chapter, the vehicle used and the tests setup are described. The second chapter presents the model that was calculated for the system and the controller that was designed. The third chapter shows then the results that were obtained with the validation of the system on road tests, after its implementation on a real vehicle. Some conclusions are then presented on the last section.

\section{VEHICLE AND TEST ENVIRONMENT}

The vehicle used on this project was a Volkswagen Polo Sedan 2004, manual, with a $2.0 \mathrm{~L}$ internal combustion engine (it is worth mentioning that the ACC developed on this paper can also be applied on other vehicles variants, as long as the plant model and the controller are redesigned according to the vehicle's dynamics). This vehicle's engine control unit (ECU) was replaced with an open-source ECU, shown on Figure 1, developed by the Automotive Engineering Group (group formed by researchers members of Escola Politécnica da USP and of Faculdade de Tecnologia de Santo André) [12]. This unit is capable of executing the same functions the original ECU does, along with some new functions, which have been implemented over the last 6 years of 
improving, such as open loop torque control, electronic throttle valve positioning control, supervisory software for computers, eco mode, etc. [13], [14].

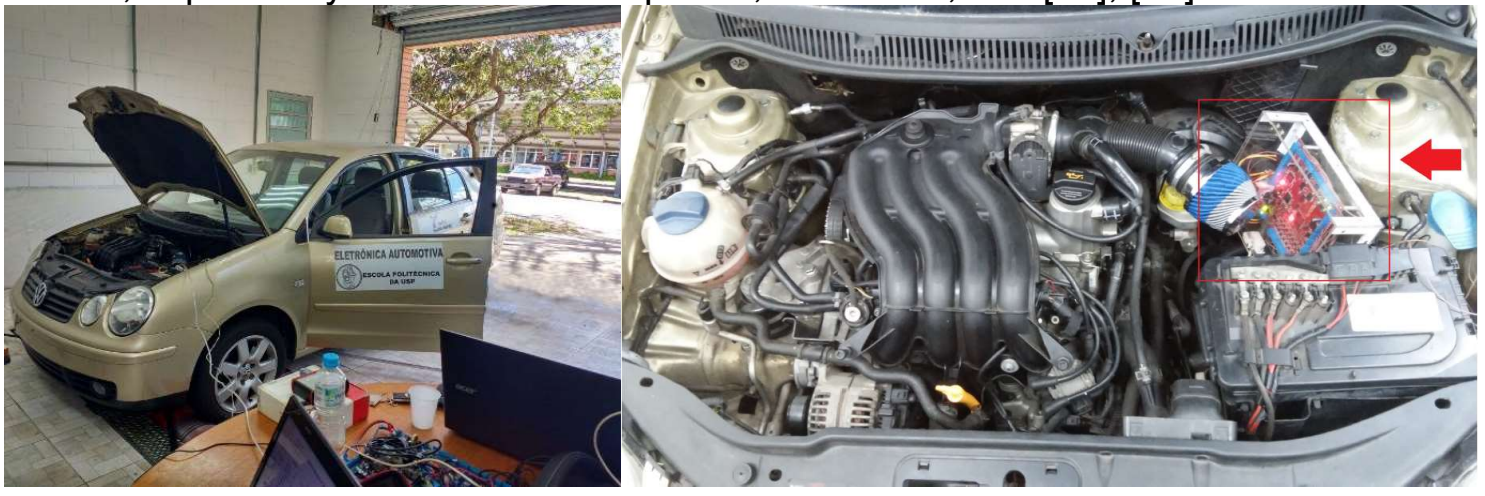

Figure 1: Test vehicle and customized ECU

Some custom CAN messages were also implemented on this ECU, in order to facilitate the development of assistance systems, and are shown on the Table 1. The message with ID 590 (HEX) has several relevant parameters from the vehicle operation, such as current speed and current position of throttle pedal. The messages with ID 200 (HEX) and 201 (HEX) are for setting different operation modes and for operating the throttle pedal via CAN network.

Table 1 - ECU customized messages

\begin{tabular}{|c|c|c|c|c|c|c|c|c|}
\hline ID & Byte 0 & Byte 1 & Byte 2 & Byte 3 & Byte 4 & Byte 5 & Byte 6 & Byte 7 \\
\hline \multirow{4}{*}{$0 \times 590$} & \multirow{4}{*}{\multicolumn{2}{|c|}{$\begin{array}{c}\text { Ref. Torque } \\
0-100 \% \\
\text { Fator } 0,01\end{array}$}} & \multirow{4}{*}{\multicolumn{2}{|c|}{$\begin{array}{c}\text { Velocidade Medida } \\
\text { Fator } 0,01 \\
\mathrm{Km} / \mathrm{h}\end{array}$}} & \multirow{4}{*}{$\begin{array}{l}\text { Marcha Engatada } \\
0 \text { (neutro) - } 5\end{array}$} & $\begin{array}{l}\text { Pedal_Embreagem } \\
\text { @bit } 00 \text { obo000000011 } \\
\text { Press.0 Solto }\end{array}$ & \multirow{4}{*}{$\begin{array}{l}\text { Ref. Cruzeiro } \\
\text { Fator } 1,0 \\
\mathrm{Km} / \mathrm{h}\end{array}$} & \multirow{4}{*}{$\begin{array}{c}\text { Erro de Hardware } \\
0 \text { - Sem erro } \\
>0 \text { - Erro detectado }\end{array}$} \\
\hline & & & & & & $\begin{array}{l}\text { Pedal_Freio } \\
\text { @bit } 10 \text { boo0000010 } \\
\text { 1Press.0 Solto }\end{array}$ & & \\
\hline & & & & & & $\begin{array}{c}\text { Modo_Cruzeiro } \\
\text { @bit } 2 \text { obo00000100 } \\
1 \text { ligado. } 0 \text { desligado }\end{array}$ & & \\
\hline & & & & & & $\begin{array}{l}\text { Modo_Pedal_Sim } \\
\text { @bit } 3 \text { ob000001000 } \\
1 \text { ligado, } 0 \text { desligado }\end{array}$ & & \\
\hline $0 \times 200$ & $\begin{array}{c}\text { "E" } \\
\text { Token de seguranç̧a }\end{array}$ & $\begin{array}{c}\text { "C" } \\
\text { Token de segurança }\end{array}$ & $\begin{array}{c}\text { "U" } \\
\text { Token de seguranç̧a }\end{array}$ & $\begin{array}{c}\text { Pedal Simulado } \\
0-100 \% \\
0-255\end{array}$ & & & & \\
\hline $0 \times 201$ & $\begin{array}{c}\text { "E" } \\
\text { Token de seguranç̧a }\end{array}$ & $\begin{array}{c}\text { "C" } \\
\text { Token de seguranç̧a }\end{array}$ & $\begin{array}{c}\text { "U" } \\
\text { Token de segurança }\end{array}$ & $\begin{array}{l}\text { Modo_Pedal_Sim } \\
1 \text { Liga, } 0 \text { Desliga }\end{array}$ & $\begin{array}{l}\text { Modo_Operação } \\
1 \text { Econom, } 0 \text { Normal }\end{array}$ & $\begin{array}{c}\text { Modo_Ref_Mlenta } \\
0-11 \\
0=800 R P M, \\
\text { M. Lenta (RPM) }=600 \\
+\left(\text { dada-1) }{ }^{5} 50\right.\end{array}$ & & \\
\hline
\end{tabular}

For the relative distance and the relative speed measurement, an automotive radar ARS3-A from Continental was installed on the front bumper of the vehicle. This component, whose name derives from "Radio Detection and Ranging", uses reflex patterns from radio waves and the Doppler effect in order to determine the distance and the speed of objects on different directions [15]. The sensor, which operates at 77 $\mathrm{GHz}$, can measure the distance to objects up to $200 \mathrm{~m}$ away, with a $0.25 \mathrm{~m}$ accuracy and can communicate to the vehicle via CAN network, at a frequency of $666 \mathrm{kHz}$.

The ACC module, shown on Figure 2, communicates with the ECU and with the automotive radar via CAN network. The module is composed of three identical nodes, each one with a PIC16F877A, as the central microprocessor, a MCP2515 (CAN controller), a PCA82C251 (CAN transceiver), LEDs, a LCD module and connectors for digital and analog I/Os. Only the $\mathrm{B}$ node (central) and the $\mathrm{C}$ node (right one) were used for this project. On the B node was located the central processing, programmed on the 
PIC microcontroller, and the CAN bus from node $B$ was connected to the ECU. On the node $\mathrm{C}$, only the CAN controller, the CAN transceiver, the digital I/Os and the CAN bus were used to stablish communication between the automotive radar and the node B. The ECU and the radar were connected to separate networks because they communicate at different frequencies, $500 \mathrm{kHz}$ and $666 \mathrm{kHz}$ respectively.

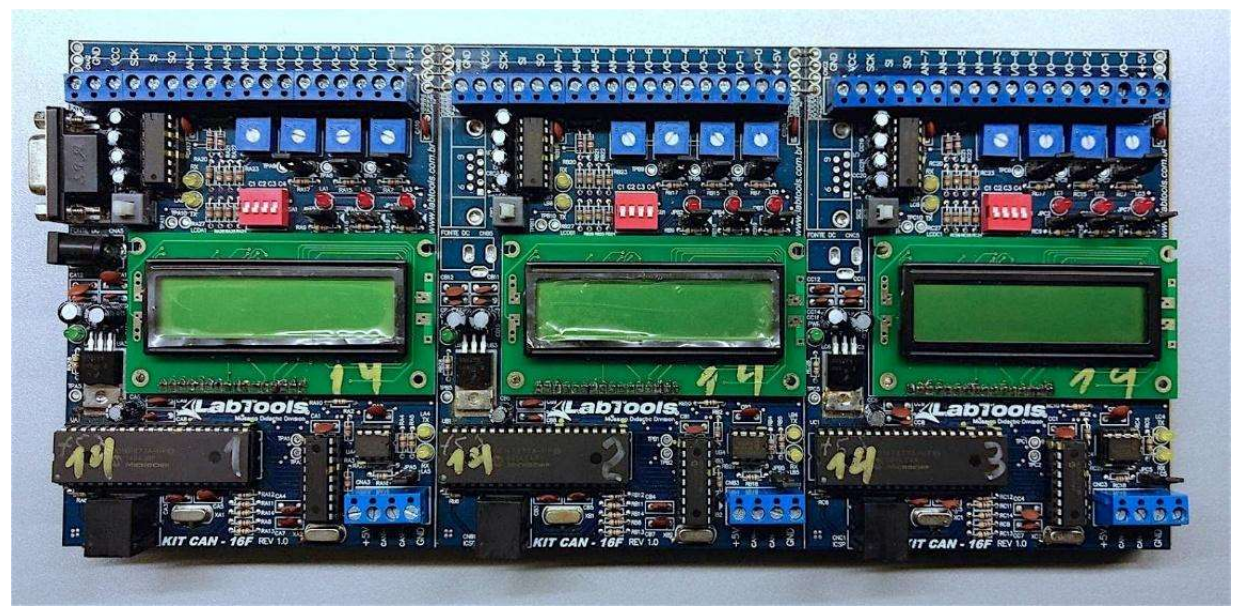

Figure 2: ACC module

\section{SYSTEM IDENTIFICATION AND CONTROL}

The vehicle used does not have any brake-by-wire technologies or electronic braking systems, such as ESP or ESC. Therefore, the speed reduction is done via engine braking. For the model, the only control input is the throttle pedal position, which ranges from $0 \%$ (pedal released) to $100 \%$ (pedal pressed all the way down), and the output is the controlled vehicle speed.

The system identifications is done via step response. As the vehicle is manual and the ACC module does not have control over the gear box, the operation of the system was restricted to only one gear. The third gear was chosen as the operating gear due to its good speed range.

Initially, for the identification of the system, experiments were performed on an inertial dynamometer, analyzing the step response of the system for an input with amplitude of 20 (representing $20 \%$ of the maximal acceleration).

As the system step response represents a typical first order model's step response, as shown on Figure 3, the transfer function from Equation 1 was calculated from the experiments.

$$
G(s)=\frac{2.23}{2.8 s+1} e^{-0.5 s}
$$




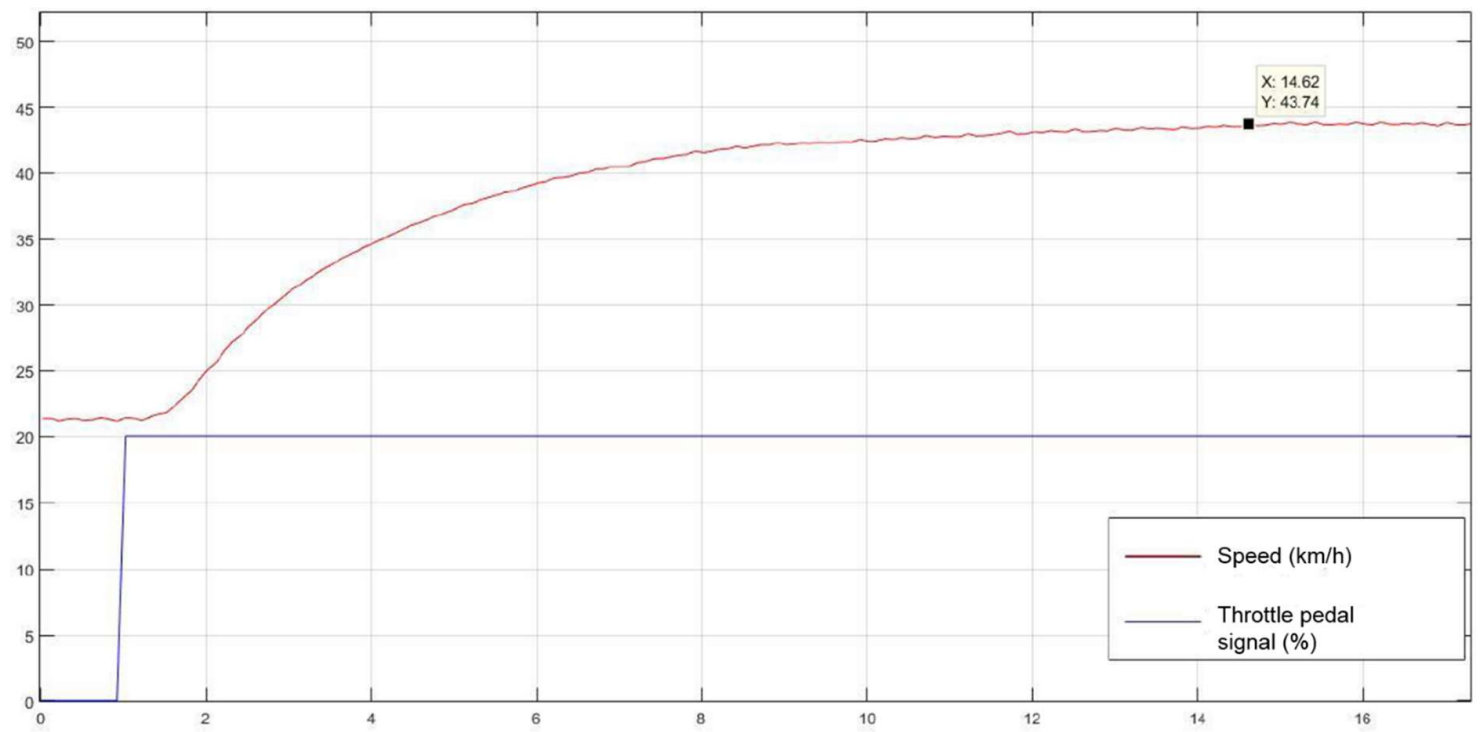

Figure 3: System step response on the dynamometer

A time delay of $0.5 \mathrm{~s}$ was also identified, caused by internal dynamics of the actuator.

The same experiment was reproduced on the road, in order to get a more precise model, with the influence of dissipative forces, such as the drag resistance. The results are shown on Figure 4.

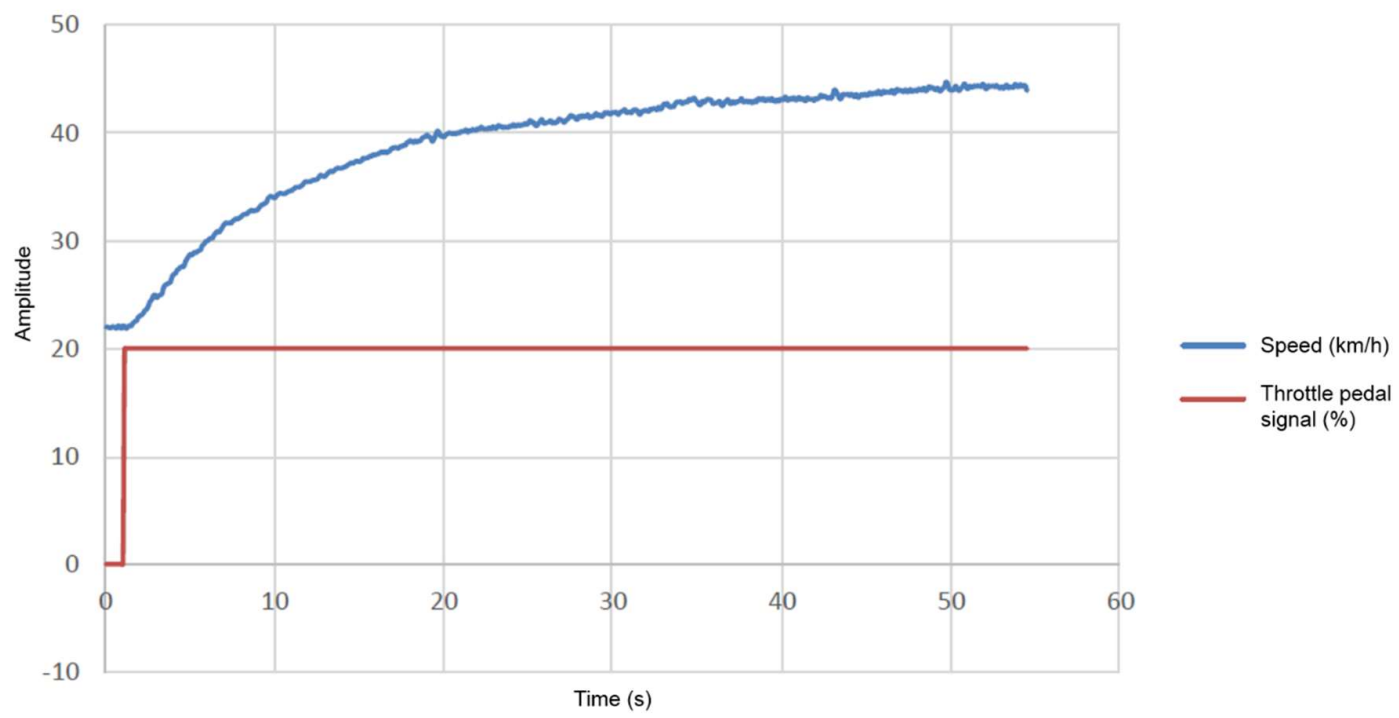

Figure 4: System step response on the road

From this experiment, the transfer function was calculated and is represented on Equation 2.

$G(s)=\frac{2.22}{12 s+1} e^{-0.5 s}$ 
The control design can be divided into two separate loops, one outer loop and one inner loop.

The inner loop is responsible for the speed control and the system inputs are the vehicle speed and the speed setpoint. Regarding the speed control requirements, the system must have zero steady-state error, rise time smaller than 10 s and settling time smaller than 15s. In addition, as an extra requirement, the control input was limited to $45 \%$, so as to maintain the passenger comfort. Considering the requirements and the dynamics of the plant, a PI controller is enough to achieve this objective.

For the first model, of the vehicle on the inertial dynamometer, it is used a proportional gain of 0.9 and an integral gain of 0.3 for the controller. Therefore, Equation 3 represents the controller's transfer function.

$$
C(s)=0.9+\frac{0.3}{s}
$$

For the second model, of the vehicle on the road, using the same requirements for the control design, Equation 4 represents the PI controller designed:

$$
C(s)=1.2+\frac{0.3}{s}
$$

The outer loop, on the other hand, is responsible for determining the speed setpoint for the inner loop. This velocity setpoint must be calculated in order to maintain a safety distance from the vehicle ahead, should there be one, and can never be faster as the maximum speed determined by the driver.

When there is no leader vehicle or when the leader vehicle is travelling faster than the speed determined by the driver, the setpoint speed for the inner loop is equal to the speed setted by the driver.

On the other cases, the setpoint speed is determined by Equation 5 , where $v_{l}$ is the speed from the leader vehicle, $d$ is the current relative distance between the two vehicles, $d_{r e f}$ is the setpoint for the distance, that is, is the safety distance that should be maintained between the vehicles, and $k_{p}$ is a proportional gain for the distance control. Higher values for $k_{p}$ make the system more oscillatory but lower values slow the system response.

$$
v=v_{l}-k_{p} *\left(d-d_{\text {ref }}\right)
$$

Figure 5, below, shows the control diagram of the implemented system, as described. 


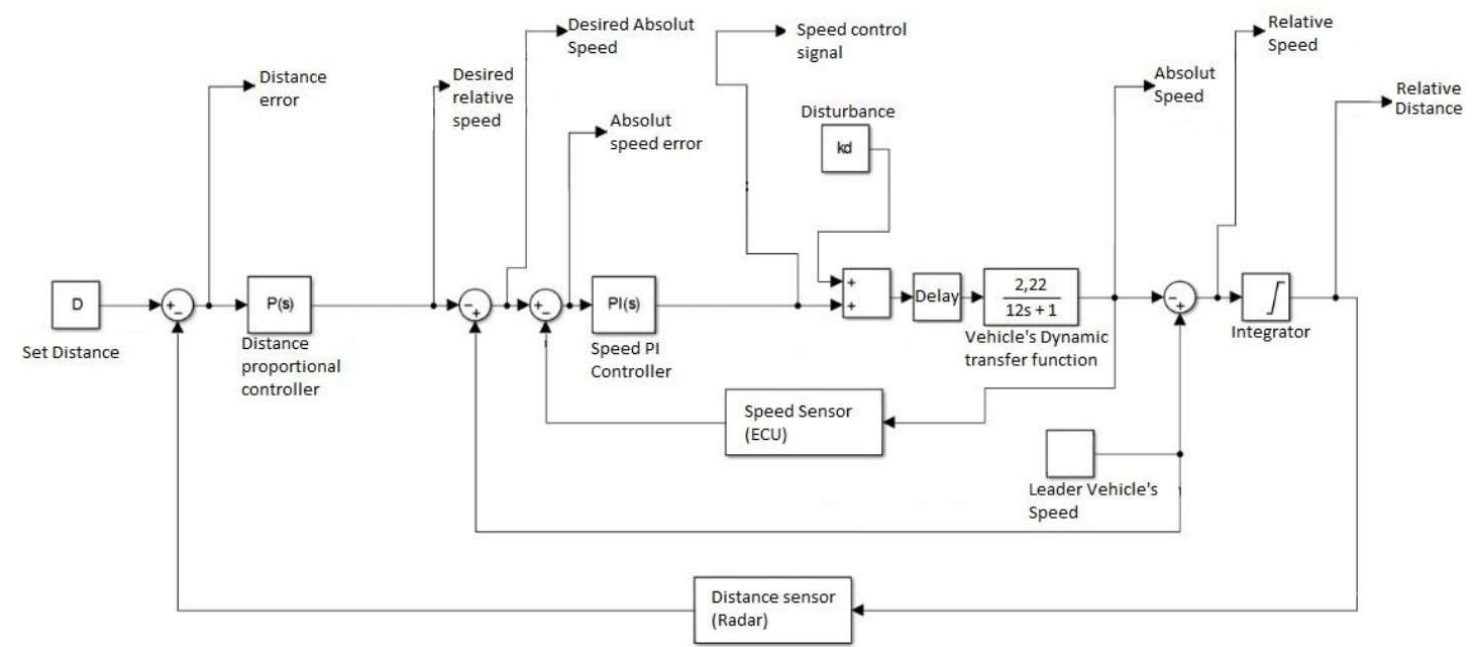

Figure 5: System Control Diagram

\section{EXPERIMENTAL RESULT}

The system went through tests on the road, under normal operating conditions and verifying several different scenarios. For all the tests, the safety distance was configured as $24 \mathrm{~m}$ and the setpoint speed determined by the driver was $45 \mathrm{~km} / \mathrm{h}$ (except for the final experiment, where the setpoint speed was reduced to $40 \mathrm{~km} / \mathrm{h}$ ).

For the first scenario, the leader vehicle was travelling at around $25 \mathrm{~km} / \mathrm{h}$ and started around $85 \mathrm{~m}$ ahead of the controlled vehicle. As it can be seen on Figure 6 and on Figure 7, the controlled vehicle reduces its speed and follows the leader vehicle without brusque accelerations or decelerations. In addition, the relative distance was controlled, with the error going from around $22.6 \%$ on the 30 s mark to around $6.6 \%$ on the 40s mark.
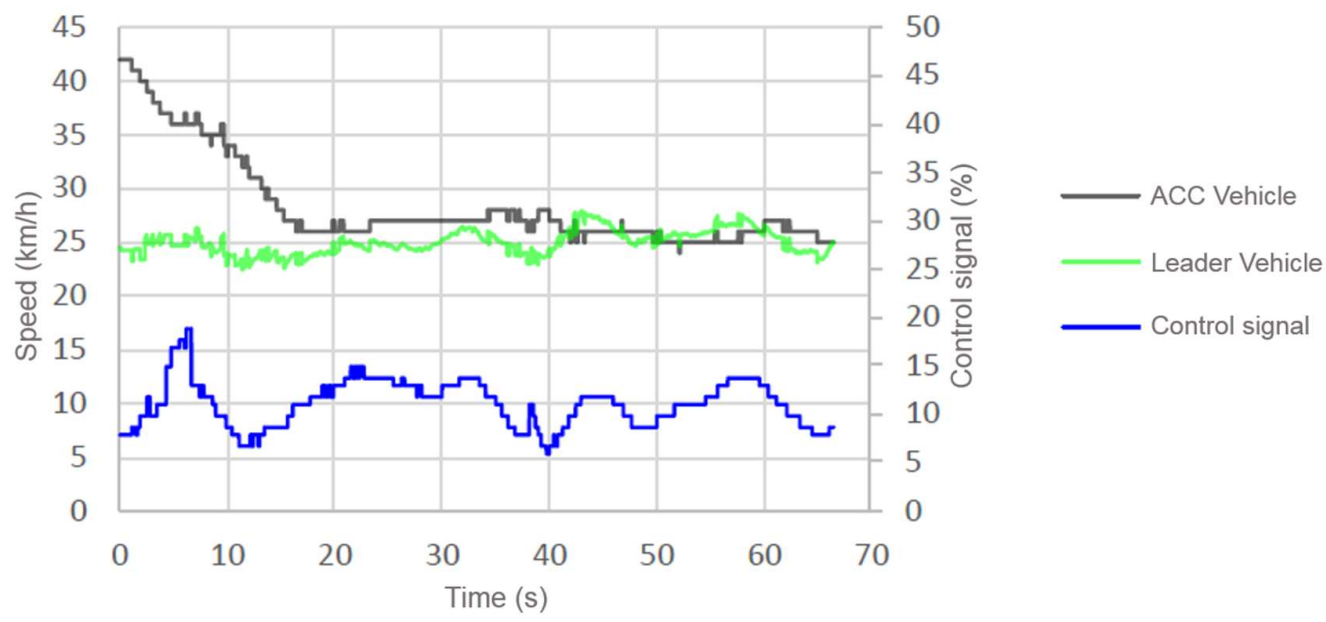

Figure 6: Scenario 1, vehicle's speed and control signal 


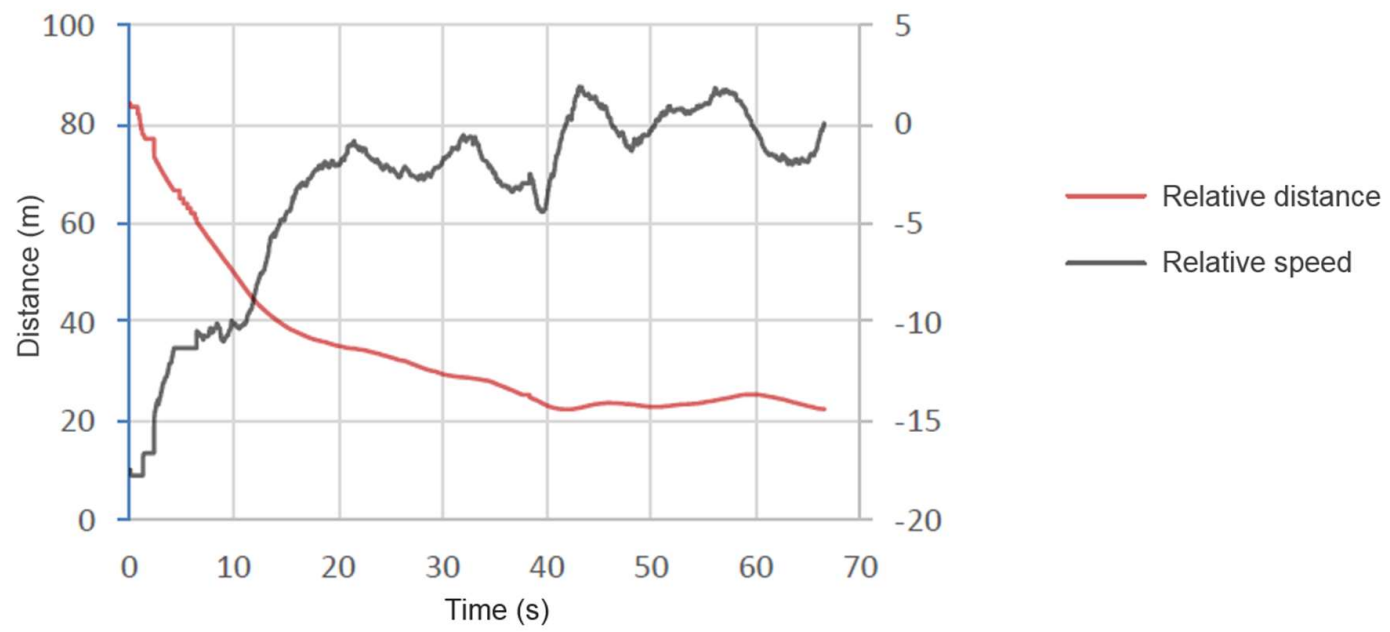

Figure 7: Scenario 1, relative distance and relative speed

The second scenario has the same conditions from the first test, but the road has an inclination of approximately $3^{\circ}$ upwards. As presented on Figure 8 and on Figure 9 , the system needs a higher control output to compensate for the inclination, but is still able to accomplish the performance requirements.

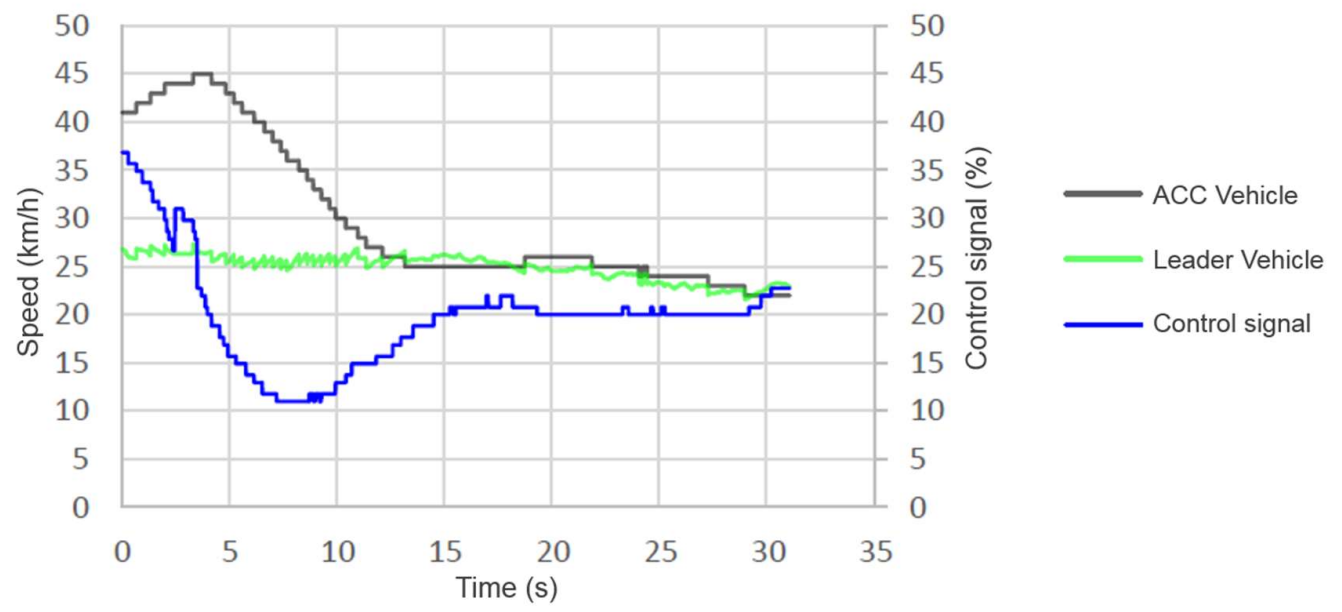

Figure 8: Scenario 2, vehicle's speed and control signal 


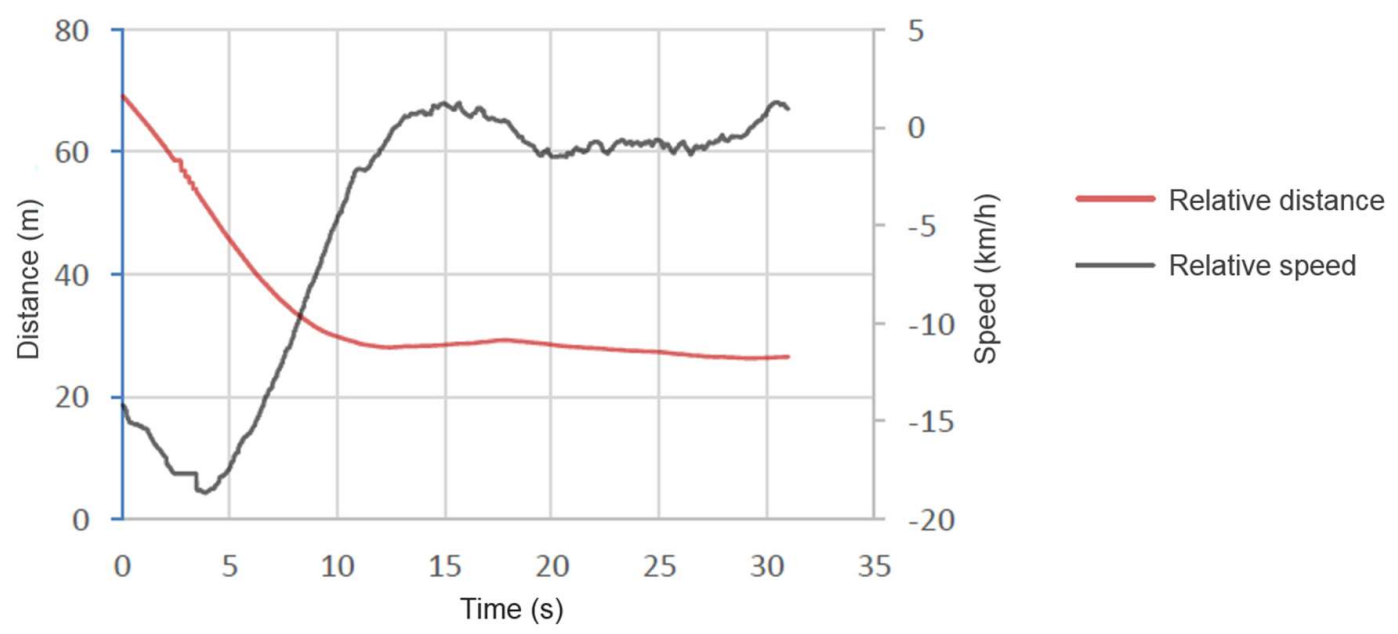

Figure 9: Scenario 2, relative distance and relative speed

For the third scenario, both vehicles start around the same speed, $36 \mathrm{~km} / \mathrm{h}$, but the relative distance is initially closer as the safety distance, around $12.5 \mathrm{~m}$. As shown on Figure 10 and on Figure 11, the controlled vehicle initially reduces its speed, in order to adjust the safety distance, and then starts following the leader vehicle.

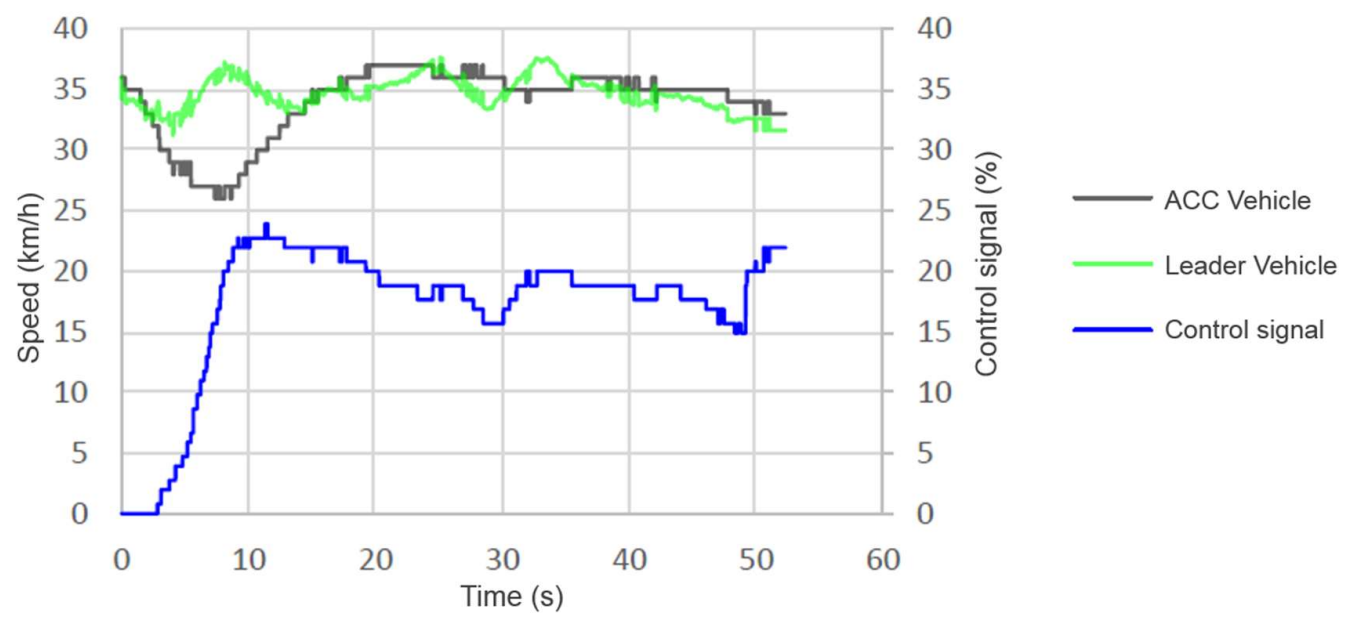

Figure 10: Scenario 3, vehicle's speed and control signal 


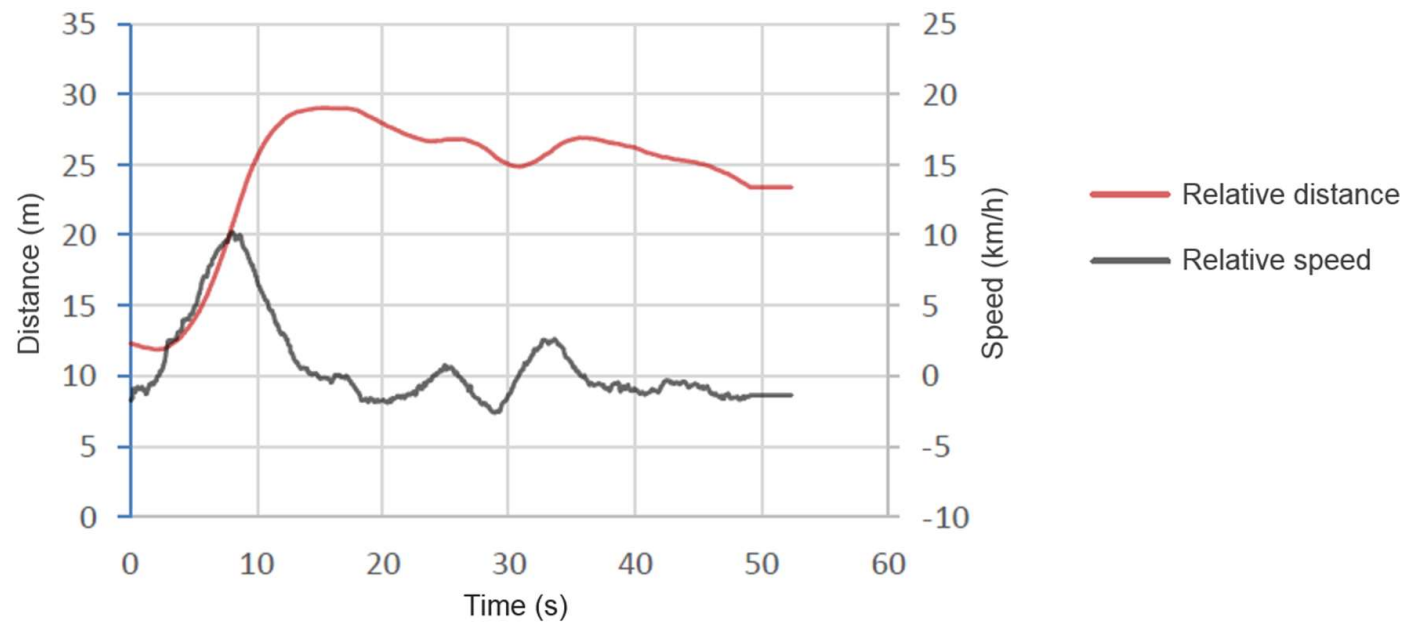

Figure 11: Scenario 3, relative distance and relative speed

On the fourth scenario, the leader vehicle starts at $25 \mathrm{~km} / \mathrm{h}$, slower as the desired setpoint speed for the controlled vehicle. After 10s, the leader vehicle accelerates to $35 \mathrm{~km} / \mathrm{h}$, still slower as the $45 \mathrm{~km} / \mathrm{h}$ speed that was setted for the controlled vehicle. As expected, the controlled vehicle is able to follow the leader vehicle, even when it changes its current speed, while effectively maintaining the safety distance. The results can be seen on Figure 12 and on Figure 13.

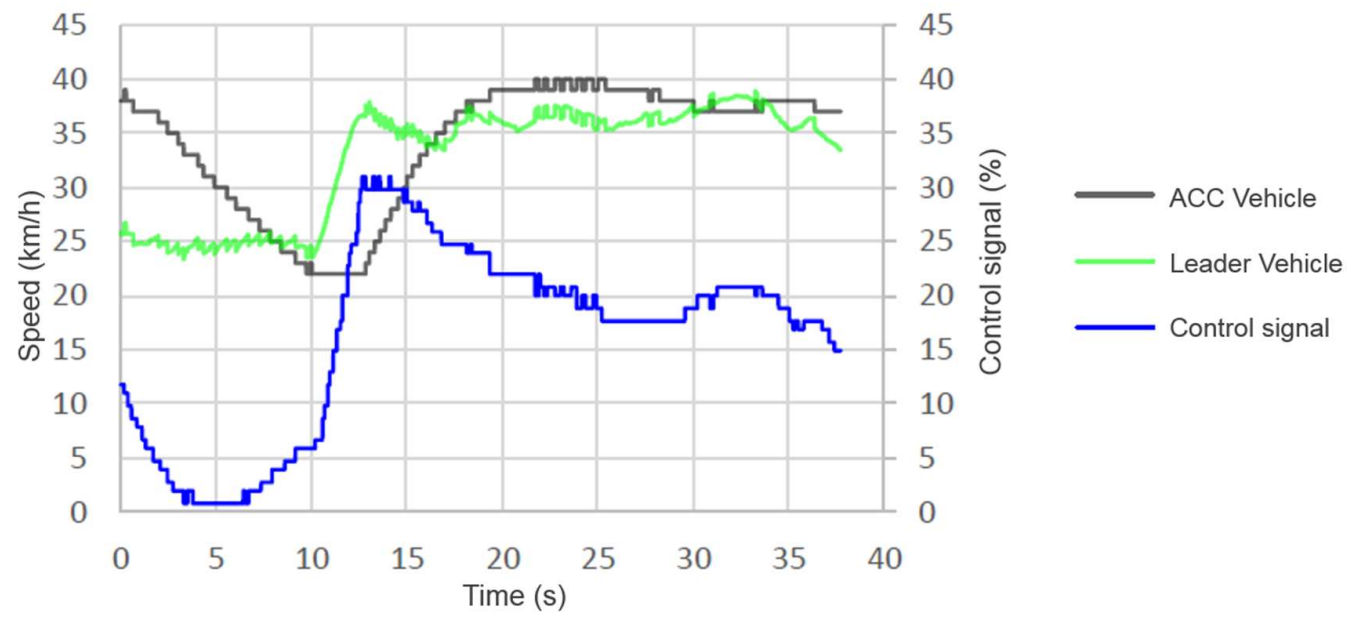

Figure 12: Scenario 4, vehicle's speed and control signal 


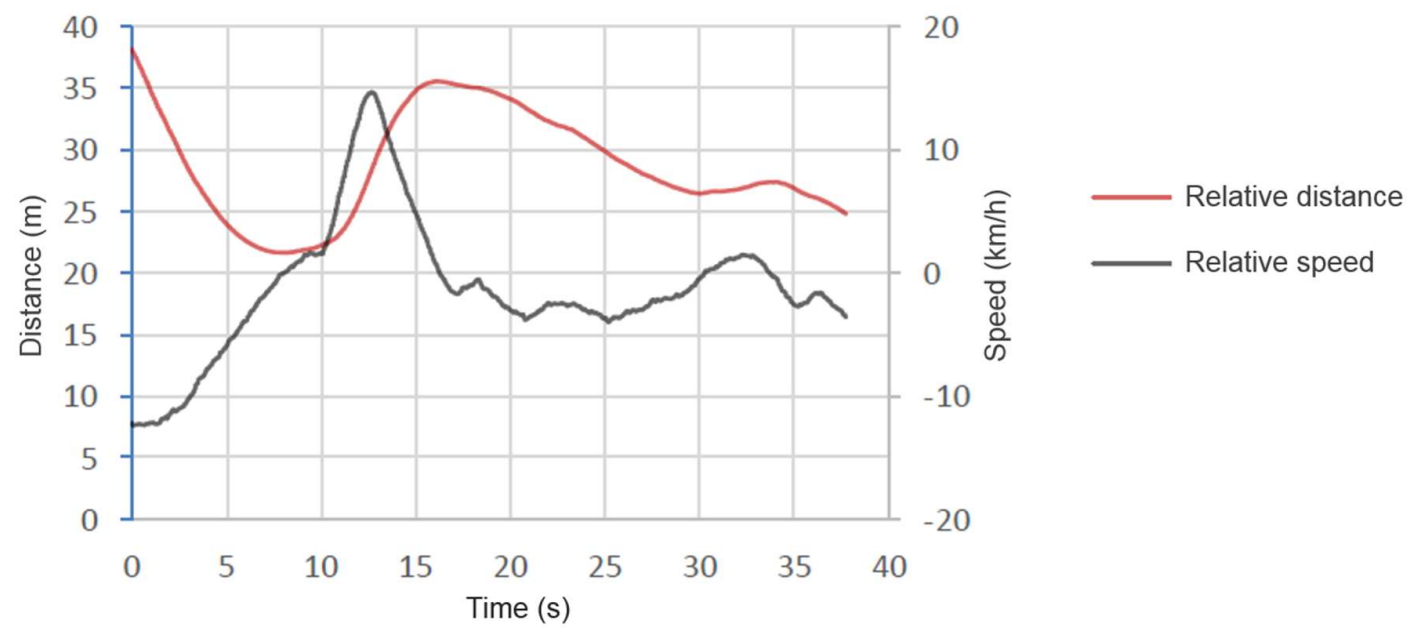

Figure 13: Scenario 4, relative distance and relative speed

The fifth scenario repeats the conditions presented on the fourth scenario, with a leader vehicle that starts slower than the controlled vehicle, but accelerates afterwards. On this test, although the leader vehicle had a more oscillatory behavior, the controlled vehicle was able to maintain a stable speed, without oscillating together with the leader vehicle, as shown on Figure 14 and on Figure 15.

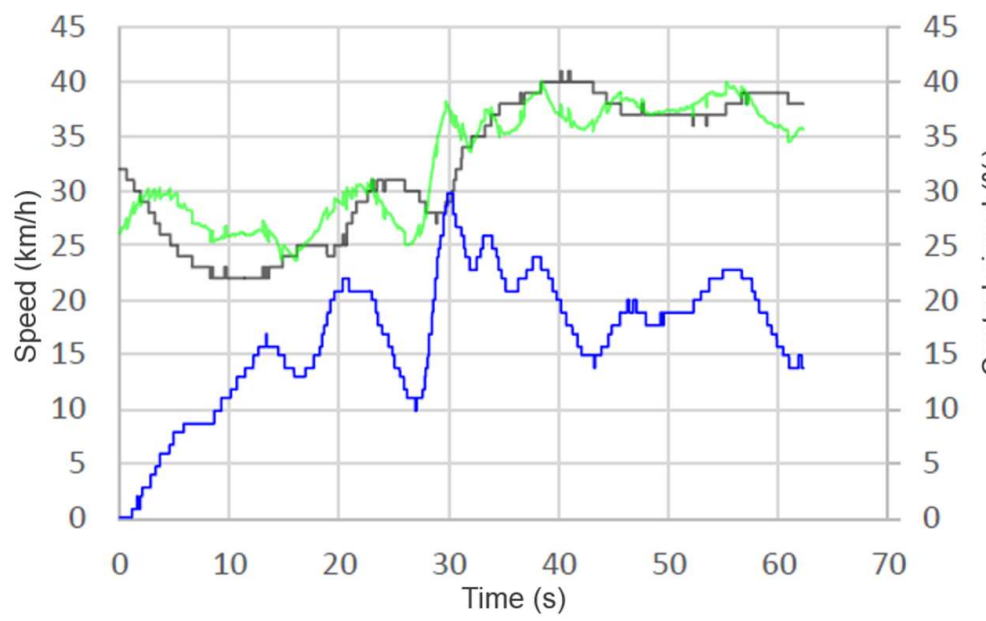

Figure 14: Scenario 5, vehicle's speed and control signal 


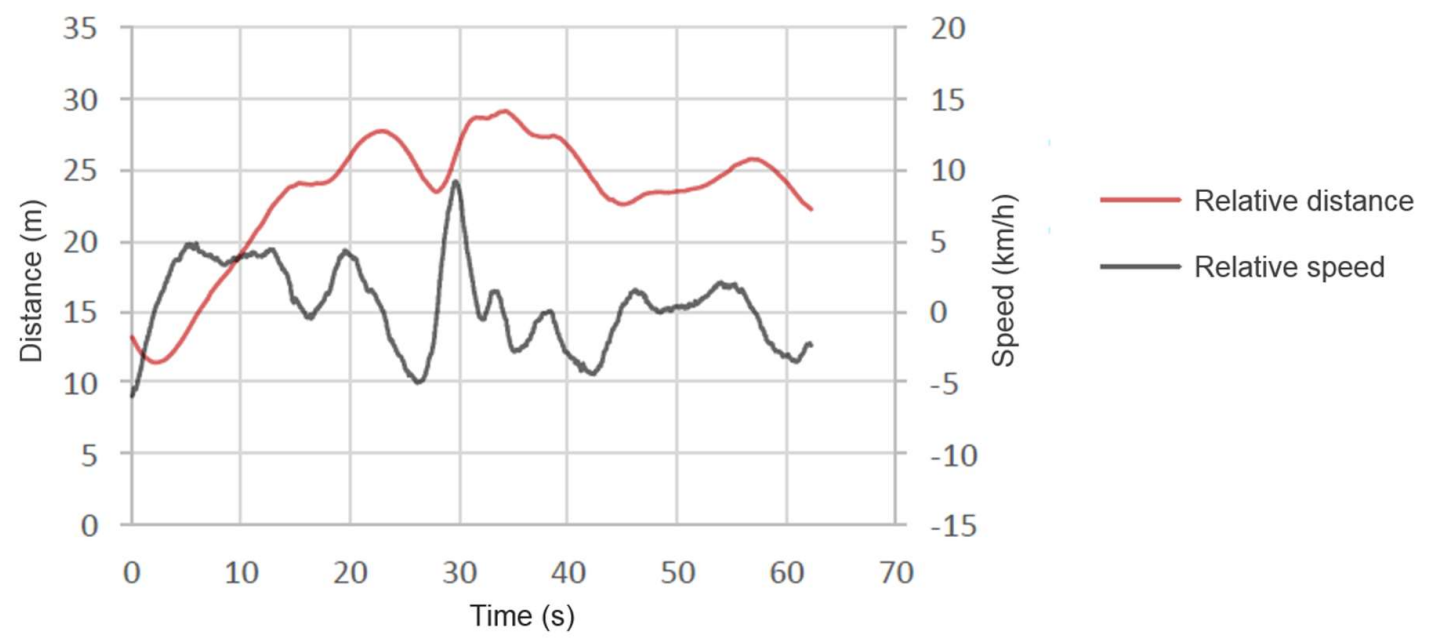

Figure 15: Scenario 5, relative distance and relative speed

For the final experiment, the setpoint speed for the controlled vehicle was reduced to $40 \mathrm{~km} / \mathrm{h}$ and the test was performed on a road with a $3^{\circ}$ inclination upwards. On this scenario, the leader vehicle starts at $30 \mathrm{~km} / \mathrm{h}$ and then accelerates afterwards to more than $50 \mathrm{~km} / \mathrm{h}$. Figure 16 and Figure 17 show that the controlled vehicle is able to maintain the safety distance and, even after the leader vehicles exceeds the setpoint speed, the controlled vehicle maintained the maximal speed of $40 \mathrm{~km} / \mathrm{h}$.

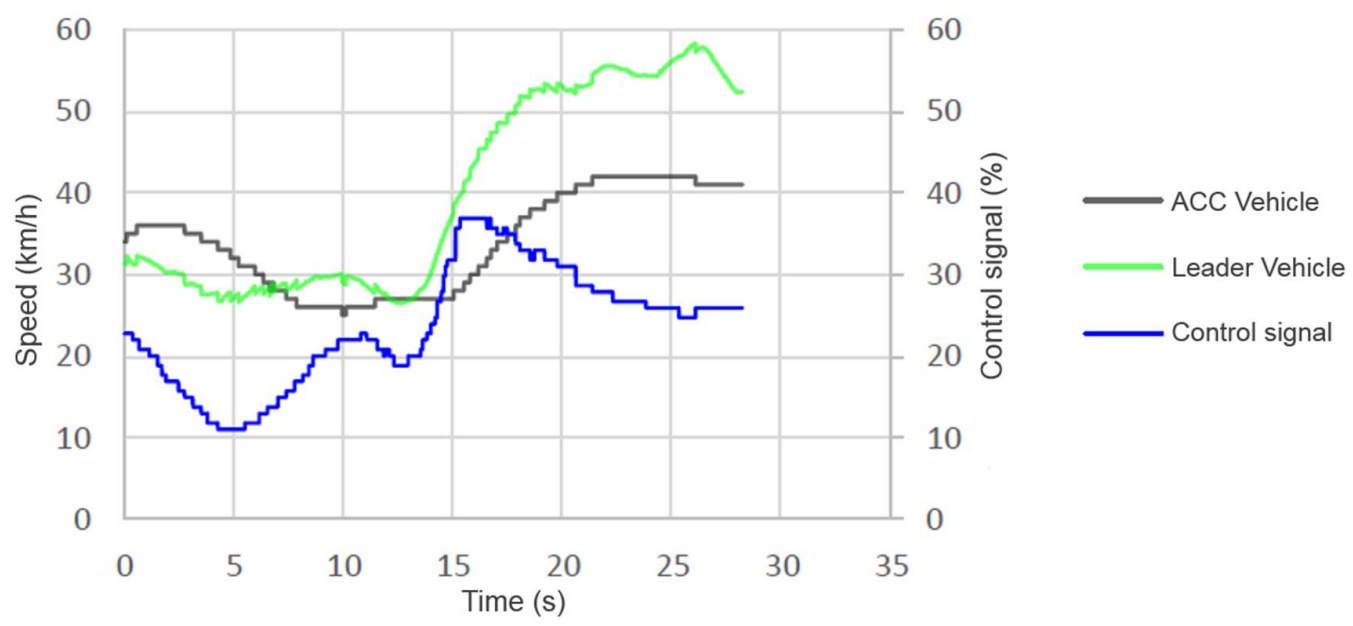

Figure 16: Scenario 6, vehicle's speed and control signal 


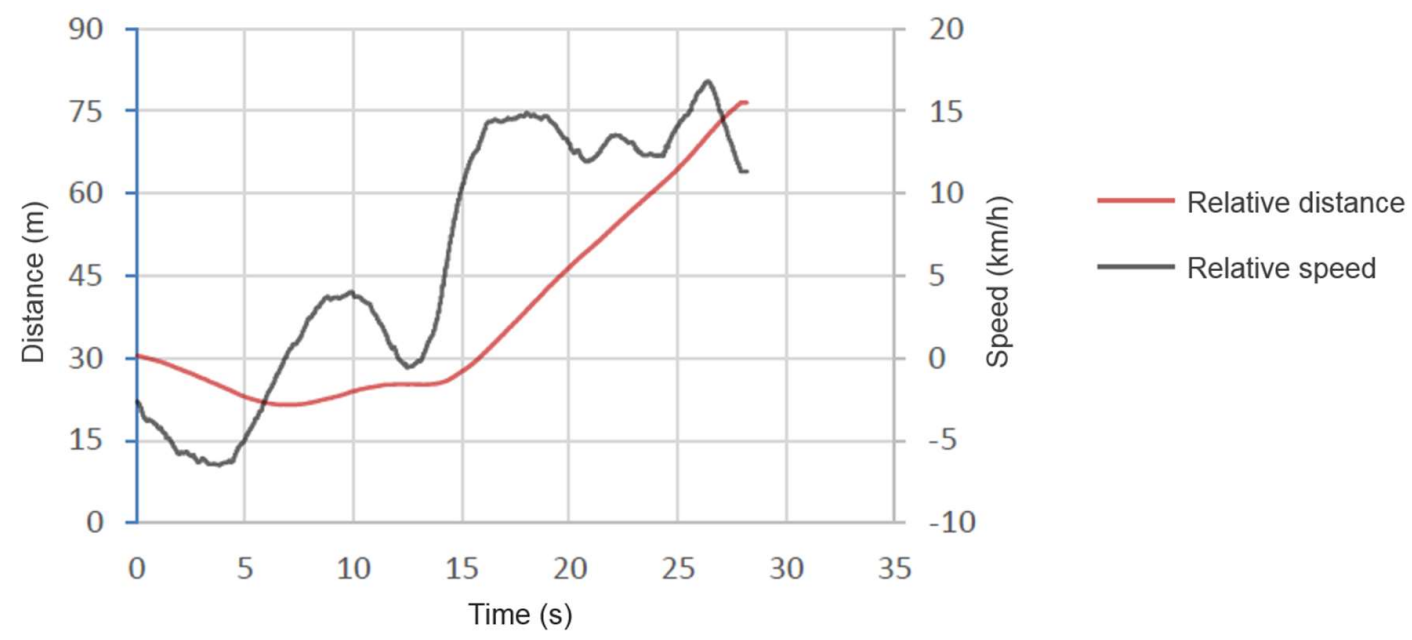

Figure 17: Scenario 6, relative distance and relative speed

\section{CONCLUSIONS}

This paper presented the development of an Adaptive Cruise Control System, which was successfully implemented on a real vehicle. Experimental validation on road tests showed that this system performed as expected, according to the safety standards applied to the system and to the speed limit determined by the user, being able to control the distance and the velocity on all six scenarios, having a good disturbance rejection and having no steady state error.

Although this systems increases the comfort of the driver, supporting him on the task of controlling the vehicle acceleration, it is worth mentioning that the driver's attention to the road and to the obstacles ahead should be maintained, as this systems is not able to identify vehicles coming from side lanes, or the presence of curves on the road. This system also has some restrictions, as the operating is limited to only the engaged gear, caused by the fact that the vehicle is manual, which means that the system cannot change gears, in addition to the fact that the ACC module is not able to actively break the vehicle.

\section{REFERENCES}

[1] WORLD HEALTH ORGANIZATION. Global status report on road safety 2018. Geneva: World Health Organization, 2018. Licence: CC BY-NC-SA 3.0 IGO. ISBN 978-92-4-156568-4. Available at https://www.who.int/violence injury prevention/road safety status/2018/en/. Access on April 15 $5^{\text {th }}, 2019$.

[2] BOULKROUNE, B.; VAN AALST, S.; LEHAEN, K.; DE SMET, J. Observer-based Controller with Integral Action for Longitudinal Vehicle Speed Control. 2017 IEEE Intelligent Vehicles Symposium (IV). Los Angeles: DOI: 10.1109/IVS.2017.7995739. 2017. p. 322 - 327. 
[3] LI, S.E., GUO, Q., XU, S., DUAN, J., LI, S., LI, C., Su, K.: Performance enhanced predictive control for adaptive cruise control system considering road elevation information. IEEE Transactions on Intelligent Vehicles 2(3), 150\{160 (2017). DOI 10.1109/TIV.2017.2736246. 2017.

[4] BENALIE, N.; PANANURAK, W.; THANOK, S.; PARNICHKUN, M. Improvement of Adaptive Cruise Control System based on Speed Characteristics and Time Headway. The 2009 IEEE/RSJ International Conference on Intelligent Robots and Systems, St Louis, USA, Oct. 2009.

[5] CORONA, D.; DE SCHUTTER, B. Adaptive Cruise Control for a SMART Car: Comparision Benchmark for MPC-PWA Control Methods. IEEE Transactions on Control Systems Technology, Vol. 16, №2, Mar. 2008.

[6] SHAKOURI, P.; CZECZOT, J.; ORDYS, A. Simulation Validation of Three Nonlinear Model-Based Controllers in the Adaptive Cruise Control System. Journal of Intelligent and Robotic Systems, Vol.8, Issue 2, pp. 207-229, Nov 2015.

[7] PANANURAK, W.; THANOK, S.; PARNICHKUM, M. Adaptive Cruise Control for an Intelligent Vehicle. 2008 IEEE International Conference on Robotics and Biomimetics, Bangkok, 2009, pp. 1794 - 1799. DOI 10.1109/ROBIO.2009.4913274. March, 2009

[8] DAVIS, L. C. Effect of adaptive cruise control systems on traffic flow. Physical review. E, Statistical, nonlinear, and soft matter physics. 69. 066110. DOI 10.1103/PhysRevE.69.066110. July 2004.

[9] PIAO, J.; MCDONALD, M. Advanced Driver Assistance Systems from Autonomous to Cooperative Approach. Transport Reviews, Vol. 28. DOI: 10.1080/01441640801987825. 2008. p. 659 - 684. August 2008.

[10] VOLLRATH, M.; SCHLEICHER, S.;GELAU, C. The influence of Cruise Control and Adaptive Cruise Control on driving behaviour - A driving simulator study. Accident; analysis and prevention. 43. 1134-9. 10.1016/j.aap.2010.12.023. May 2011.

[11] KHAYYAM, H.; NAHAVANDI, S.; DAVIS, S. Adaptive cruise control look-ahead system for energy management of vehicles. Expert systems with applications, vol. 39, no. 3, pp. 3874-3885. Feb. 2012.

[12] PEREIRA, B. C. F. Unidade de Gerenciamento Eletrônico de um Motor Volkswagen 2.0L: Projeto Otto II. Bachelor's thesis, Escola Politécnica da Universidade de São Paulo. 2013.

[13] PEREIRA, B. S. Controle da Mistura Ar/Combustível em um Motor a Combustão Interna: Sistema em Malha Fechada. Master's thesis, Escola Politécnica da Universidade de São Paulo. 2015 
[14] PEREIRA, B. C. F. Evolução de uma Unidade de Gerenciamento Eletrônico de um Motor VW 2.0L e Desenvolvimento de Controle de Cruzeiro: Projeto Otto IV. Master's thesis, Escola Politécnica da Universidade de São Paulo. 2017.

[15] ALTERA. Intel. Implementing Digital Processing for Automotive Radar Using SoCs, 2013. Available at: https://www.intel.com/content/dam/alterawww/global/en US/pdfs/literature/wp/wp-01183-automotive-radar-socfpga.pdf. Acess on April 20th, 2019. 